Check for updates

Cite this: Mater. Chem. Front., 2019, 3, 1593

Received 11th April 2019, Accepted 28th May 2019

DOI: $10.1039 / \mathrm{c} 9 \mathrm{qm} 00227 \mathrm{~h}$

rsc.li/frontiers-materials

\section{A diphenylamino-substituted cationic cyclometalated Ir(III) complex: its aggregation- induced phosphorescent emission and oxygen sensing properties $\dagger$}

\author{
Lei Wang, ${ }^{a}$ Zhanming Gao, ${ }^{a}$ Chun Liu (D) *a and Xin Jin (D) ${ }^{b}$
}

\begin{abstract}
A cationic cyclometalated Ir(III) complex, Ir2, with aggregation-induced phosphorescent emission (AIPE) has been prepared and fully characterized. The effects of the diphenylamino (DPA) group on the photophysical properties, redox properties and oxygen sensing behaviors of the $\operatorname{Ir}($ III) complex were investigated systematically, and compared with non-DPA-substituted complex Ir1. The results show that the introduction of an electron-donating DPA group at the 4-position on the phenyl ring of the cyclometalating ligand affects the HOMO levels of the corresponding $\operatorname{Ir}(\mathrm{III})$ complex significantly, resulting in a marked decrease in the energy gap. DPA-substituted Ir $\mathbf{2}$ demonstrates obvious aggregation-induced phosphorescent emission, while non-DPA-substituted Ir1 is AIPE-inert. The phosphorescence oxygen sensing properties of both complexes were studied in polymer films, and fast response time and excellent operational stability were observed. Two-site model fitting results indicate that Ir2 exhibits higher sensitivity to $\mathrm{O}_{2}$ than that of Ir1. The DPA-substituted cationic cyclometalated Ir(III) complex is a potential candidate for efficient luminescent oxygen sensing.
\end{abstract}

\section{Introduction}

Cyclometalated Ir(III) complexes have attracted much attention due to their high quantum yields, ${ }^{1,2}$ large Stokes shifts, ${ }^{3,4}$ and photo- and thermal stabilities ${ }^{5,6}$ as well as the easy tunability of their properties. ${ }^{7,8}$ So far, these complexes have been widely studied for their potential applications in organic electroluminescent devices, photocatalysis, cell imaging, analytical probing and so on. ${ }^{9,10}$ However, like other transition metal complexes, $\operatorname{Ir}(\mathrm{III})$ complexes usually suffer from low luminescence efficiency in the solid or aggregated state, due to aggregation-caused quenching (ACQ) ${ }^{11}$ which significantly limits their applications in many fields. Several approaches including surface fixation, and intercalation into transparent clay membranes have been employed to conquer the ACQ effect but with limited success. ${ }^{12,13}$ In 2001, Tang et al. discovered an aggregation-induced emission (AIE) phenomenon of silole derivatives, which was of great interest to the scientific community. ${ }^{14}$ AIE is a special photophysical phenomenon of luminescent materials, which overcomes the limitation that ACQ-active materials cannot be used for solid-state

\footnotetext{
${ }^{a}$ State Key Laboratory of Fine Chemicals, Dalian University of Technology, Linggong Road 2, Dalian 116024, China. E-mail: cliu@dlut.edu.cn

${ }^{b}$ Eco-chemical Engineering Cooperative Innovation Center of Shandong, Qingdao University of Science and Technology, Qingdao 266042, China

$\dagger$ Electronic supplementary information (ESI) available. See DOI: 10.1039/c9qm00227h
}

luminescence applications. Since then, a lot of AIE-active organic luminophores have been reported..$^{15-18}$ In 2002, Manimaran et al. found that $\operatorname{Re}(\mathrm{I})$ tricarbonyl complexes with pyridine ligands exhibited phosphorescence enhancement by rigidification, which was the first example of metal-based luminophores with aggregation induced phosphorescent emission (AIPE). ${ }^{19}$ The first in-depth investigation on the AIPE mechanism of cyclometalated Ir(III) complexes was reported by $\mathrm{Li}$ and co-workers in 2008, and they found that the aggregation phosphorescence enhancement was mainly dependent on the structures of ancillary ligands in the complexes. ${ }^{20}$ The first example of an AIPE-active cationic iridium complex was reported by $\mathrm{Su}$, Liao and co-workers in 2011. These AIPE-active compounds, with carbazole units at the 4 and 7 positions of the phenanthroline ancillary ligands, feature a dendrimer-like structure. ${ }^{21}$ Consequently, a number of AIPE-active Ir(III) compounds with different molecular structures were developed in the past few years. ${ }^{22-32}$

Cyclometalated Ir(III) complexes are particularly suitable for use as oxygen-sensitive probes (OSPs) in luminescence oxygen sensing, due to their outstanding optical properties. In 1996, Marco and co-workers ${ }^{33}$ reported the first use of an $\operatorname{Ir}(\mathrm{III})$ complex as the active species in a luminescent oxygen sensor, which attracted much attention and lots of Ir(III) complexes as OSPs have been reported successively thereafter. ${ }^{34-37}$ We have a long-term interest in disclosing the relationship between the molecular structures of the cyclometalated metal complexes 
and their oxygen sensing properties. A series of platinum(II) and iridium(III) complexes as efficient OSPs have been synthesized and investigated. ${ }^{5,37-42}$ In this paper, a new diphenylamino (DPA)-substituted cationic bis-cyclometalated $\operatorname{Ir}(\mathrm{III})$ complex with AIPE properties was synthesized, which was used to explore the effects of the DPA group on the photophysical and electrochemical properties of the corresponding Ir(III) complex. In addition, the oxygen sensitivity and operational stability of the $\operatorname{Ir}(\mathrm{III})$ complex were studied.

\section{Results and discussion}

\subsection{Synthesis and characterization of the complexes}

Chemical structures and the detailed synthetic protocols of the $\operatorname{Ir}(\mathrm{III})$ complexes are shown in Scheme 1. Cyclometalating ligands $\mathbf{L 1}$ and $\mathbf{L} 2$ were prepared efficiently via a palladiumcatalyzed ligand-free and aerobic Suzuki-Miyaura reaction in aqueous ethanol developed by our group. ${ }^{43}$ Both of the $\operatorname{Ir}($ III) complexes were synthesized via a three-step route: cyclometalated Ir(III) $m$-chloro-bridged dimers were first obtained, followed by treatment with 1,10-phenanthroline, and then a counterion exchange reaction from $\mathrm{Cl}^{-}$to $\mathrm{PF}_{6}{ }^{-}$. The corresponding characterization data for the $\operatorname{Ir}(\mathrm{III})$ complexes are presented in the Experimental section.

\subsection{Photophysical properties}

UV-vis absorption spectra and emission spectra of Ir1 and Ir2 in $\mathrm{CH}_{2} \mathrm{Cl}_{2}\left(1.0 \times 10^{-5} \mathrm{M}\right)$ at room temperature are presented in Fig. 1 and the related data are listed in Table 1. Similar to the previously reported cyclometalated Ir(III) complexes, both complexes exhibit strong absorption bands in the ultraviolet region belonging to the spin-allowed intraligand $\left({ }^{1} \pi-\pi^{*}\right)$ transitions. ${ }^{44,45}$ The long wavelength with lower extinction coefficient absorption can be assigned to spin-allowed and spin-forbidden metal-to-ligand charge-transfer transitions ( ${ }^{1}$ MLCT and ${ }^{3}$ MLCT). ${ }^{46,47}$ Fig. 1(a) shows that DPA-substituted Ir2 has a larger molar absorption coefficient than that of Ir1.

The normalized emission spectra of these complexes are shown in Fig. 1(b). The emission maxima are red-shifted $66 \mathrm{~nm}$ for Ir2 compared to Ir1, owing to the electron-donating ability of the DPA moiety. These results show that the emission of the complexes could be finely tuned by the modification of the structures of the cyclometalating ligands.

The phosphorescence lifetimes $(\tau)$ of $\operatorname{Ir} 1$ and $\mathbf{I r} 2$ in $\mathrm{CH}_{2} \mathrm{Cl}_{2}$ are $0.80 \mu \mathrm{s}$ and $0.13 \mu \mathrm{s}$ at room temperature, respectively
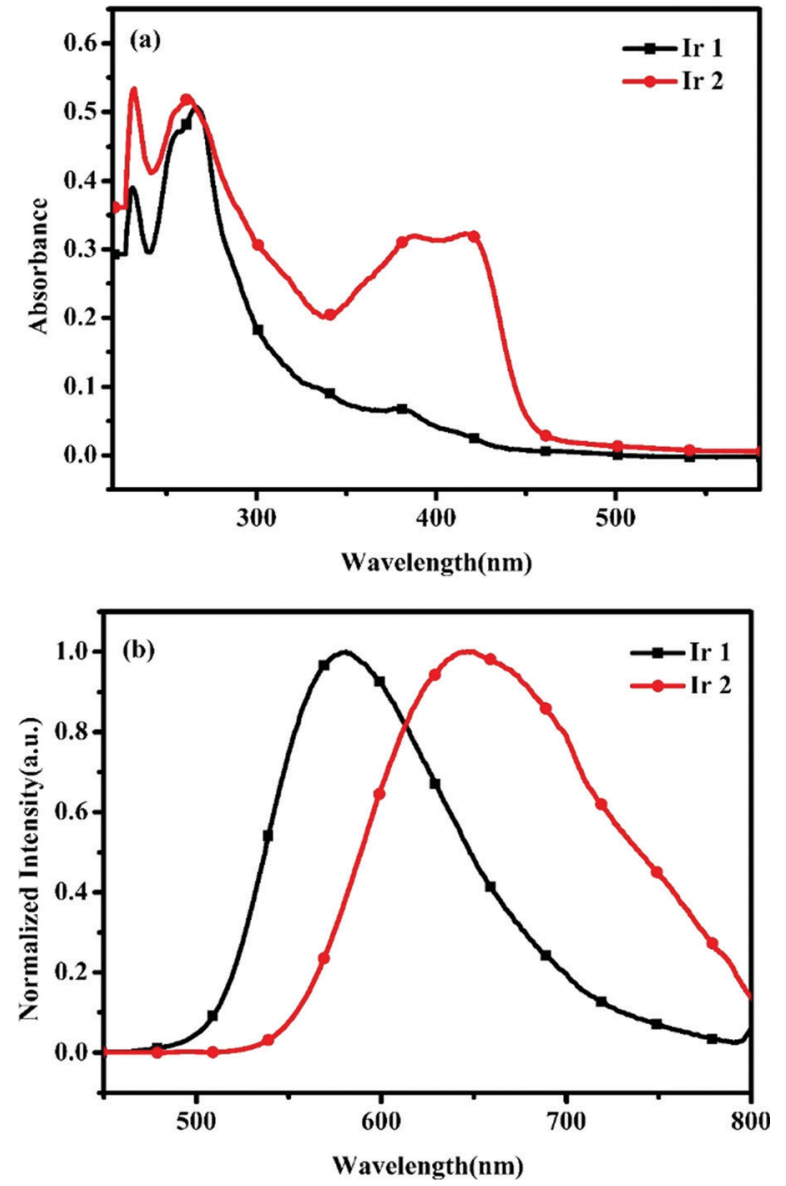

Fig. 1 Absorption (a) and emission spectra (b) of the Ir(III) complexes $\left(1.0 \times 10^{-5} \mathrm{M}\right.$ in $\left.\mathrm{CH}_{2} \mathrm{Cl}_{2}\right)$ at room temperature.

(Table 1, the phosphorescence decay profiles of the $\operatorname{Ir}($ III) complexes are provided in Fig. S2, ESI $\dagger$ ). However, the $\tau$ value for the complex with a DPA group (Ir2) shortens significantly compared with that of Ir1, which may result from large nonradiative decay caused by the rotation of the DPA group in Ir2 (see Table 1). Thus, the substituent effect of the cyclometalating ligands plays an important role in tuning the photoluminescence properties of the $\operatorname{Ir}(\mathrm{III})$ complexes.

\subsection{Aggregation-induced emission properties}

The emission spectra and photoluminescence (PL) quantum yields $\left(\Phi_{\mathrm{PL}}\right)$ of complexes Ir1 and Ir2 in different states were measured and the $\Phi_{\mathrm{PL}}$ data are summarized in Table S1 (ESI $\dagger$ ).

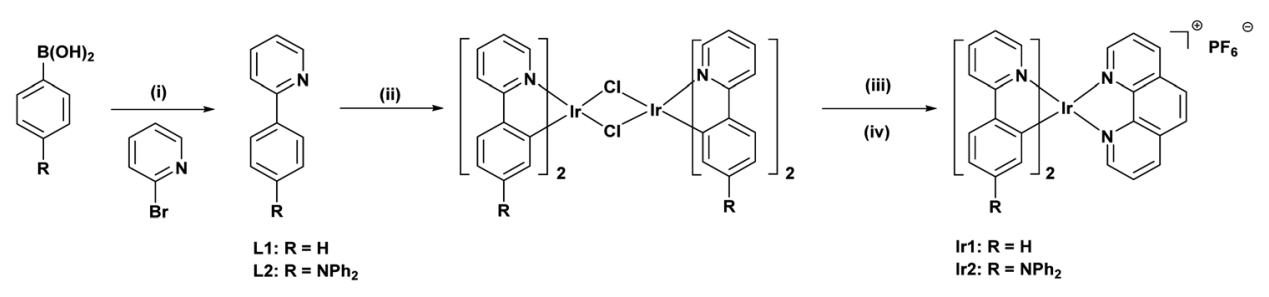

Scheme 1 Synthesis of cyclometalated $\operatorname{Ir}(\mathrm{III})$ complexes. (i) $\mathrm{Pd}(\mathrm{OAc})_{2}, \mathrm{~K}_{2} \mathrm{CO}_{3}, \mathrm{EtOH} / \mathrm{H}_{2} \mathrm{O} 3: 1(\mathrm{v} / \mathrm{v}), 80{ }^{\circ} \mathrm{C}$ in air, $30-60 \mathrm{~min}$. (ii) $\operatorname{IrCl} 3 \cdot 3 \mathrm{H}_{2} \mathrm{O}$, $\mathrm{EtOCH} \mathrm{CH}_{2} \mathrm{OH} / \mathrm{H}_{2} \mathrm{O}, 3: 1$ (v/v), $110{ }^{\circ} \mathrm{C}, \mathrm{N}_{2}, 24$ h. (iii) 1,10-Phenanthroline, EtOCH${ }_{2} \mathrm{CH}_{2} \mathrm{OH}, 120{ }^{\circ} \mathrm{C}, \mathrm{N}_{2}, 24 \mathrm{~h}$. (iv) KPF 6 , RT, 3 h. 
Table 1 Photophysical data of Ir(III) complexes Ir1 and Ir2

\begin{tabular}{|c|c|c|c|c|c|c|}
\hline Complex & $\lambda_{\mathrm{abs}}{ }^{a}(\mathrm{~nm})$ & $\lambda_{\mathrm{em}}^{b}(\mathrm{~nm})$ & $\Phi_{\mathrm{PL}}^{c}\left(\Phi_{\mathrm{PL}}\right)^{d}$ & $\tau^{e}(\mu \mathrm{s})$ & $k_{\mathrm{r}}^{f}\left(10^{5} \mathrm{~s}^{-1}\right)$ & $k_{\mathrm{nr}}^{f}\left(10^{5} \mathrm{~s}^{-1}\right)$ \\
\hline
\end{tabular}

${ }^{a}$ Measured in $\mathrm{CH}_{2} \mathrm{Cl}_{2}$ at a concentration of $10^{-5} \mathrm{~mol} \mathrm{~L}^{-1}$ and extinction coefficients $\left(10^{4} \mathrm{M}^{-1} \mathrm{~cm}^{-1}\right)$ are shown in parentheses. ${ }^{b}$ The emission maxima are the values in bold style $\left(\lambda_{\text {exc }}=410 \mathrm{~nm}\right) .{ }^{c}$ The quantum yields $\left(\Phi_{\text {solution }}\right)$ in deoxygenated $\mathrm{CH}_{2} \mathrm{Cl}_{2}$ were measured with $\left[\operatorname{Ir}(\mathrm{ppy})_{2}(\mathrm{acac})\right]$ $\left(\Phi_{\mathrm{PL}}=0.34\right)$ as a standard. ${ }^{d}$ The absolute phosphorescence quantum yields determined by employing an integrating sphere. ${ }^{e}$ In deoxygenated $\mathrm{CH}_{2} \mathrm{Cl}_{2}$ solution. ${ }^{f}$ The radiative and nonradiative decay rates of $k_{\mathrm{r}}$ and $k_{\mathrm{nr}}$ were calculated from $k_{\mathrm{r}}=\Phi_{\mathrm{PL}} \times \tau^{-1}$ and $k_{\mathrm{nr}}=\tau^{-1}-k_{\mathrm{r}}$. All results were measured at ambient temperature.

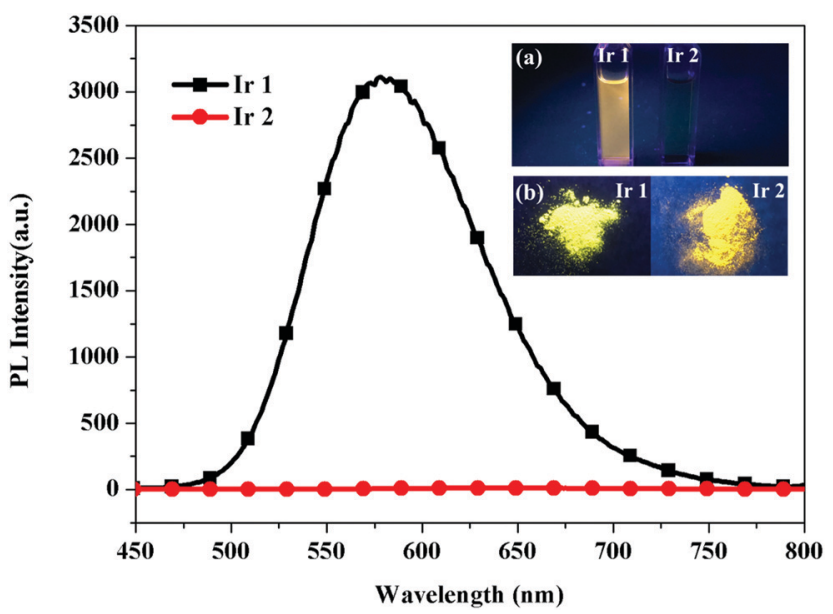

Fig. 2 Emission spectra of the $\operatorname{Ir}(\mathrm{III})$ complexes $\left(5.0 \times 10^{-5} \mathrm{M}\right.$ in $\left.\mathrm{CH}_{3} \mathrm{CN}\right)$ at room temperature. Insets: Photographs of Ir1 and Ir2 in solution and the solid state taken under a $365 \mathrm{~nm}$ lamp.

Upon illumination under a $365 \mathrm{~nm}$ UV lamp, complex Ir1 exhibits intense emission bands in acetonitrile at room temperature, while the dilute acetonitrile solution of Ir2 is almost non-emissive, which is consistent with a low value of $\Phi_{\mathrm{PL}}$, as shown in Fig. 2. In sharp contrast, bright orange lights were observed in the solid state, indicating that Ir2 probably is AIPEactive (Fig. 2(b)).

In order to further confirm the AIPE characteristics of Ir2, the emission spectra of complex Ir2 were investigated with different water fractions in a $\mathrm{H}_{2} \mathrm{O} / \mathrm{CH}_{3} \mathrm{CN}$ system. As shown in Fig. 3, almost no photoluminescence signal was recorded for Ir2 in acetonitrile, whereas the intensity of emission varied dramatically with the variation of the proportion of water in the mixed solvent. Upon adding water up to $60 \mathrm{vol} \%$, the intensity of emission was increased obviously. The phenomena could be explained by the restriction of intramolecular rotation. ${ }^{15,16}$ When Ir 2 is molecularly dissolved in a good solvent (acetonitrile), it is a weak emitter due to the very high non-radiative decay rate $\left(76.4 \times 10^{5} \mathrm{~s}^{-1}\right.$, Table 1$)$, caused by the active twisting motions of the DPA group. In contrast, when large amounts of water were added to its solution, the formation of aggregates restricts the intramolecular rotation and results in a strong phosphorescent emission. The maximum PL intensity was reached with the water content up to $70 \%$. As depicted in Fig. 3(b), the PL intensity at the

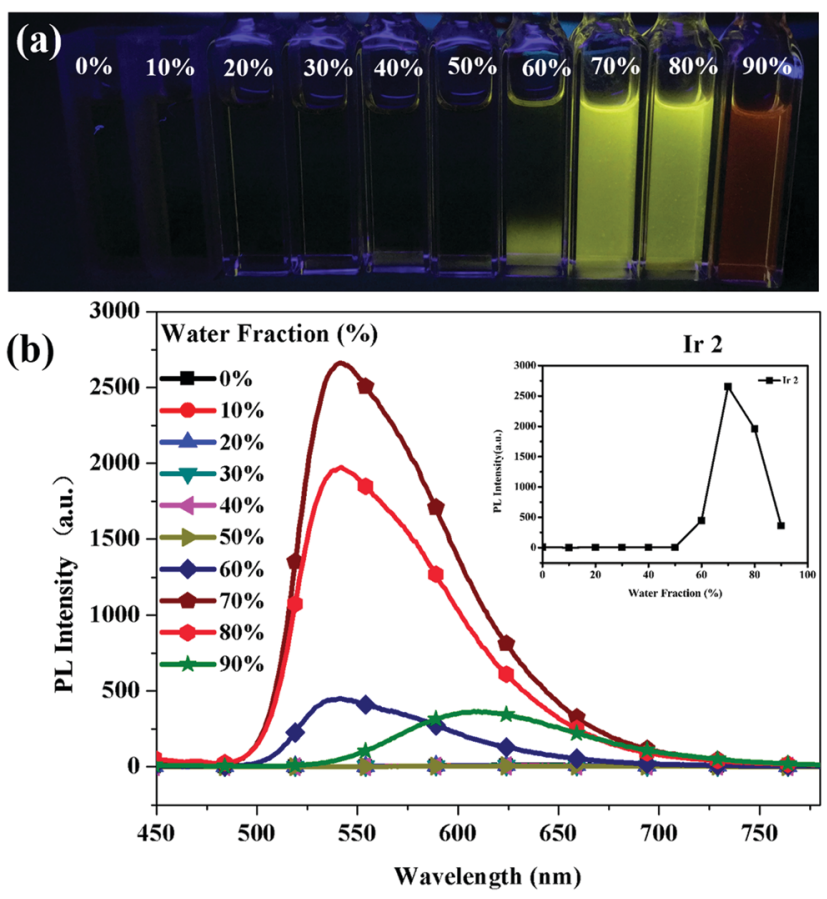

Fig. 3 Emission spectra and photographs of $\operatorname{Ir}($ III) complex Ir2 $(5.0 \times$ $10^{-5} \mathrm{~mol} \mathrm{~L}^{-1}$ ) in $\mathrm{H}_{2} \mathrm{O} / \mathrm{CH}_{3} \mathrm{CN}$ with different water fractions $(0-90 \%)$ at room temperature.

water fraction $\left(f_{\mathrm{w}}\right)$ of $70 \%$ is almost 300 times higher than that in acetonitrile. And similarly the value of $\Phi_{\mathrm{PL}}$ at the water fraction $\left(f_{\mathrm{w}}\right)$ of $70 \%$ is almost 17 times higher than that in acetonitrile (Fig. S3, ESI $\dagger$ ). However, a clear declining in trend was observed after that. There are two possible reasons for the decrease in emission intensity when water is increased to a certain fraction in the solvent system. ${ }^{48}$ The first one is that, when bigger aggregates are formed, only the molecules on the surface could be irradiated, most of them were limited internally, resulting in a weak emission intensity. Secondly, crystal particles and amorphous particles could be formed when a large amount of water is added. The former ones would enhance the emission intensity but the latter do not.

\subsection{Electrochemical properties}

The electrochemical properties of the Ir(III) complexes were studied via cyclic voltammetry (CV) and the results are listed in Table 2. During the anodic scan at the rate of $100 \mathrm{mV} \mathrm{s}^{-1}$, the 
Table 2 Electrochemical data for Ir1 and Ir2

\begin{tabular}{llllll}
\hline Complex & $E_{\text {ox }}^{\text {onset } a}[\mathrm{~V}]$ & $E_{\text {red }}^{\text {onset } a}[\mathrm{~V}]$ & $E_{\text {Hомо }}{ }^{b}[\mathrm{eV}]$ & $E_{\mathrm{LUMO}}{ }^{c}[\mathrm{eV}]$ & $E_{\mathrm{g}}{ }^{d}[\mathrm{eV}]$ \\
\hline Ir1 & 1.18 & -1.31 & -5.58 & -3.09 & 2.49 \\
Ir2 & 0.70 & -1.16 & -5.10 & -3.24 & 1.86
\end{tabular}

${ }^{a} 0.1 \mathrm{M}\left[\mathrm{Bu}_{4} \mathrm{~N}\right] \mathrm{PF}_{6}$ in $\mathrm{CH}_{2} \mathrm{Cl}_{2}$, at a scan rate of $100 \mathrm{mV} \mathrm{s}{ }^{-1}$, measured using the saturated calomel electrode (SCE) as the standard. ${ }^{b} E_{\text {HOMO }}$ $(\mathrm{eV})=-\mathrm{e}\left(4.4+E_{\text {ox }}^{\text {ont }}\right) \cdot{ }^{c} E_{\text {LUMO }}(\mathrm{eV})=-\mathrm{e}\left(4.4+E_{\text {red }}^{\text {onset }}\right) \cdot{ }^{d} E_{g}=E_{\text {LUMO }}-$ $E_{\mathrm{HO} O}$. HOMOs and LUMOs denote highest-occupied molecular orbitals and lowest-unoccupied molecular orbitals, respectively.

CVs of Ir1 and Ir2 showed oxidation potentials of $+1.18 \mathrm{~V}$ and $+0.70 \mathrm{~V}$ versus the saturated calomel electrode (SCE), respectively. This positive oxidative wave is assigned to the metal-centered $\operatorname{Ir}(\mathrm{III}) / \mathrm{Ir}(\mathrm{Iv})$ oxidation couple, in accordance with the reported cyclometalated Ir(III) systems. ${ }^{49}$ Obvious differences in the oxidative potentials were observed between non-DPA substituted Ir1 and DPA-modified Ir2. As shown in Table 2, it is found that introducing the DPA group in the benzene unit leads to a low potential for Ir2. These complexes exhibit a reduction wave at different potentials of $-1.31 \mathrm{~V}$ and $-1.16 \mathrm{~V}$, which can be assigned to the reduction of the phenanthroline ligands. The HOMO and LUMO energies can be calculated using the following equations $\left(E_{\mathrm{HOMO}}(\mathrm{eV})=-\mathrm{e}\left(4.4+E_{\mathrm{Ox}}^{\text {onset }}\right), E_{\mathrm{LUMO}}(\mathrm{eV})=-\mathrm{e}\left(4.4+E_{\text {red }}^{\text {onset }}\right)\right)$ and the results are presented in Table 2 .

\subsection{Theoretical calculations}

In order to understand the impacts of the substituent (DPA) on the properties of the Ir(III) complexes and estimate the energy levels and electron density distributions of the orbitals of Ir1 and Ir2, Density Functional Theory (DFT) calculations were performed. As reported in Fig. 4, the HOMO distribution primarily resides on the iridium center and cyclometalating ligands and the LUMO distribution is localized on the whole 1,10-phenanthroline ligand. The HOMO-LUMO gaps calculated for Ir1 and Ir2 are $3.21 \mathrm{eV}$ and $2.65 \mathrm{eV}$, respectively.

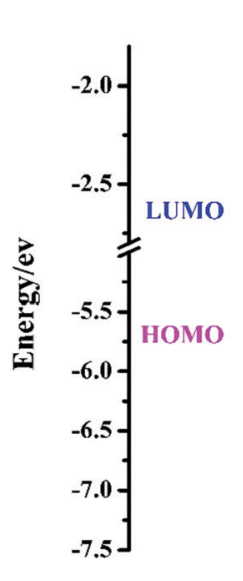

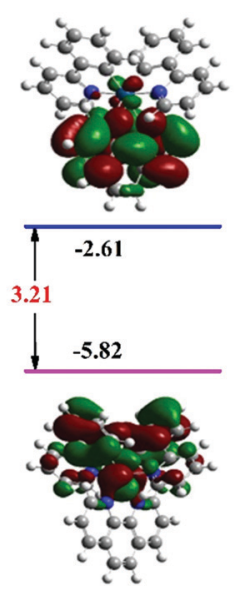

Ir1
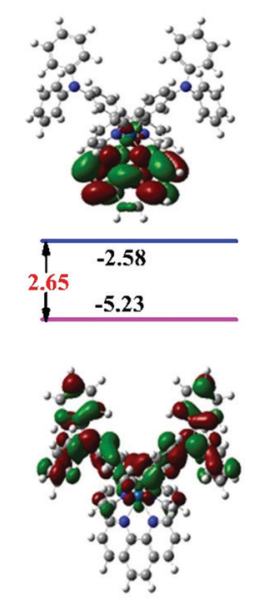

Ir2
Fig. 4 Calculated energy-level diagram and contour plots of the HOMO and LUMO for the Ir(III) complexes.
The results clearly show that the HOMO-LUMO gaps calculated for Ir1 and Ir2 are different to each other, revealing that the HOMO and LUMO levels are strongly influenced by the DPA group in the 4-position of the benzene ring, resulting in a decrease in $E_{\mathrm{g}}$ from $3.21 \mathrm{eV}$ for Ir1 to $2.65 \mathrm{eV}$ for Ir2. These results reasonably explain the red-shifts observed in the emission maxima (see Fig. 1(b)).

To investigate the nature of the emissive excited state, the low lying triplet states of these Ir(III) complexes were calculated based on their optimized geometry of the ground state $\left(\mathrm{S}_{0}\right)$ using the time-dependent approach (TD-DFT). The vertical excitation energies and molecular orbitals involved in the excitations for the lowest energy triplet states are summarized in Table 3 (see Fig. S5 in the ESI $\dagger$ for the electron density maps of the frontier molecular orbitals that are mainly involved in the lowest lying transition). TD-DFT calculations show that the emitting excited state of complexes Ir1 and Ir2 involves much more ${ }^{3}$ MLCT and ${ }^{3}$ LLCT character and different degrees of ${ }^{3} \mathrm{LC}$ character, which can explain their broad unstructured emission bands as shown in Fig. 1(b). Compared with Ir2, nonDPA substituted Ir 1 has the predominant ${ }^{3} \mathrm{LC}$ nature of the $\mathrm{T}_{2}$ state.

\subsection{Oxygen sensing properties}

The oxygen sensitivity of the Ir(III) complexes was investigated in $\mathrm{CH}_{2} \mathrm{Cl}_{2}$ first. As expected, the emission intensity of the complexes decreased with the increase of the oxygen concentration from 0 to $100 \%$. For example, changing from an $\mathrm{N}_{2}$ atmosphere to $2.17 \% \mathrm{O}_{2}$ (mixed with $\mathrm{N}_{2}$, v/v) will significantly quench the emission intensity of complex Ir1 by over $50 \%$. In addition, the shape of the emission profile without distortions under different oxygen concentrations guarantees that the decreased phosphorescence can be attributed only to the oxygen quenching process. A similar quenching effect was observed for complex Ir2 as shown in Fig. 5.

In fluid solution, the relationship between the emission intensity of the OSP and the concentration of quencher $\left(\mathrm{O}_{2}\right)$ is reflected by the Stern-Volmer equation, which can be described as eqn (1), where $I$ is the emission intensity, subscript 0 denotes the value of the quantity in the absence of a quencher, $K_{\mathrm{SV}}$ is the Stern-Volmer

Table 3 Calculated triplet states of Ir 1 and Ir $\mathbf{2}$ by using a TD-DFT approach

\begin{tabular}{llllll}
\hline Complex & State & $E^{a}(\mathrm{eV})$ & Composition $^{b}$ & $\mathrm{CI}^{c}$ & Character \\
\hline Ir1 & $\mathrm{T}_{1}$ & 2.50 & $\mathrm{H} \rightarrow \mathrm{L}$ & 0.6958 & MLCT/LLCT \\
& $\mathrm{T}_{2}$ & 2.75 & $\mathrm{H} \rightarrow \mathrm{L}+1$ & 0.6058 & MLCT/LLCT \\
& & & $\mathrm{H} \rightarrow \mathrm{L}+3$ & 0.2719 & LC \\
Ir2 & $\mathrm{T}_{1}$ & 2.20 & $\mathrm{H} \rightarrow \mathrm{L}$ & 0.6867 & MLCT/LLCT \\
& $\mathrm{T}_{2}$ & 2.26 & $\mathrm{H}-1 \rightarrow \mathrm{L}$ & 0.6932 & MLCT/LLCT \\
& $\mathrm{T}_{3}$ & 2.36 & $\mathrm{H}-1 \rightarrow \mathrm{L}+2$ & 0.3635 & MLCT/LLCT/LC \\
& & & $\mathrm{H} \rightarrow \mathrm{L}+1$ & 0.4430 & MLCT/LLCT \\
& & & $\mathrm{H} \rightarrow \mathrm{L}+3$ & 0.3529 & MLCT/LLCT
\end{tabular}

${ }^{a}$ Only the selected low-lying excited states are presented. ${ }^{b}$ Only the main configurations are presented. $\mathrm{H}$ and $\mathrm{L}$ denote HOMOs and LUMOs, respectively. ${ }^{c}$ The configuration-interaction (CI) coefficients are absolute values. Oscillator strengths are zero because of the neglect of spin-orbit coupling in the TD-DFT calculations. 

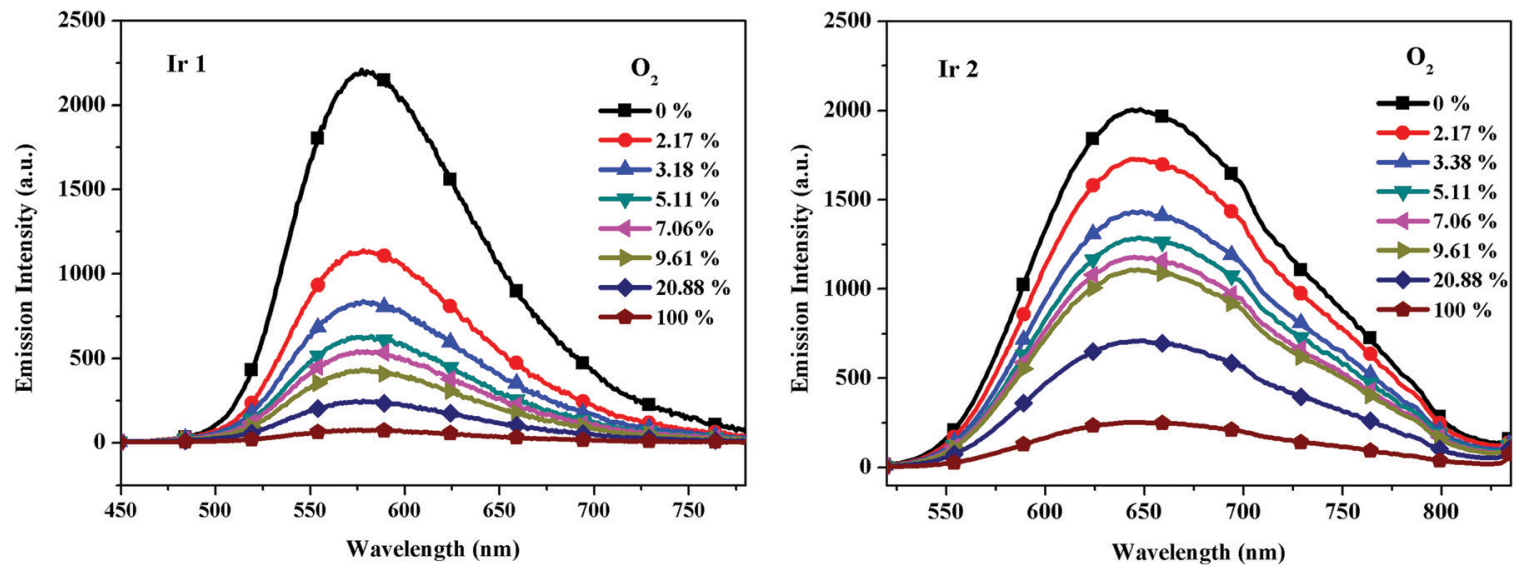

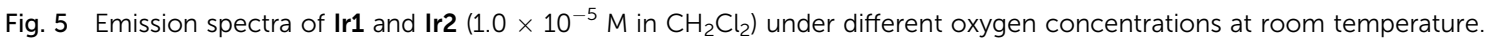

quenching constant and $\mathrm{Po}_{2}$ is the partial pressure of oxygen.

$$
\frac{I_{0}}{I}=\frac{\tau_{0}}{\tau}=1+K_{\mathrm{Sv}} p_{\mathrm{O}_{2}}
$$

The $I_{0} / I_{100}$ value is used to evaluate the $\mathrm{O}_{2}$ sensing properties of phosphorescent OSPs, where $I_{0}$ and $I_{100}$ represent the detected luminescence intensities in the $100 \% \mathrm{~N}_{2}$ and $100 \%$ $\mathrm{O}_{2}$ atmosphere. The $I_{0} / I_{100}$ values of these $\operatorname{Ir}(\mathrm{III})$ complexes in $\mathrm{CH}_{2} \mathrm{Cl}_{2}$ are 29.2 and 7.9, respectively. Stern-Volmer plots are shown in Fig. S6 (ESI $\dagger$ ). The results show that AIPE-active Ir2 is not an efficient OSP in $\mathrm{CH}_{2} \mathrm{Cl}_{2}$.

To obtain an oxygen sensor for continuous monitoring of molecular oxygen, the oxygen sensitive probe is usually incorporated in a thin layer of matrix polymer ethyl cellulose (EC). This is because EC is easily penetrated by oxygen with a permeability coefficient $P$ of $1.1 \times 10^{-12} \mathrm{~cm}^{2} \mathrm{~Pa} \mathrm{~s}^{-1}$ and has an excellent processability in common organic solvents. ${ }^{50}$ It is regarded as a standard host material with good long-term stability and commercial availability for oxygen sensing. In this work the oxygen sensitivity of the $\operatorname{Ir}($ III) complexes was also studied in EC films. According to eqn (2), the quenching behaviors of Ir1 and Ir2 were analyzed at various oxygen concentrations. For a heterogeneous oxygen sensing film, a modified Stern-Volmer plot is usually required to quantify the quenching effect. A two-site model was proposed by Demas and co-workers, ${ }^{51,52}$ which has been generally accepted and widely used ever since. ${ }^{53,54}$ In the two-site model, the OSP takes into account (at least) two distinctly different environments, one $\left(f_{1}\right)$ being quenchable, the other $\left(f_{2}\right)$ either not being quenched at all, or being quenched at a very different rate $\left(f_{1}+f_{2}=1\right)$. Each component shows different quenching constants $\left(K_{\mathrm{SV} 1}\right.$ and $\left.K_{\mathrm{SV} 2}\right)$.

$$
\frac{I_{0}}{I}=\frac{\tau_{0}}{\tau}=1+\frac{f_{1}}{1+K_{\mathrm{SV} 1} p_{\mathrm{O}_{2}}}+\frac{f_{2}}{1+K_{\mathrm{SV} 2} p_{\mathrm{O}_{2}}}
$$

where $I_{0}$ and $I$ are the emission intensities of a probe in the absence and presence of oxygen, respectively. $P_{\mathrm{O}_{2}}$ is the partial pressure of oxygen. The weighted quenching constant $K_{\mathrm{SV}}^{\mathrm{app}}\left(K_{\mathrm{SV}}^{\mathrm{app}}=\right.$ $K_{\mathrm{SV} 1} \cdot f_{1}+K_{\mathrm{SV} 2} \cdot f_{2}$ ) is a guide of the sensitivity of an oxygen sensor, and higher values indicate that the sensor is more sensitive to

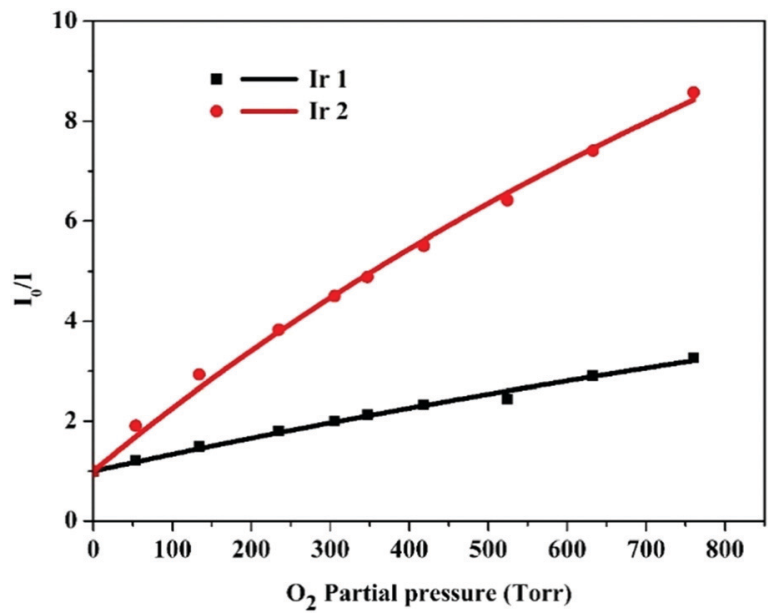

Fig. 6 Stern-Volmer plots for oxygen sensing films of the $\operatorname{Ir}(\mathrm{III})$ complexes immobilized in EC (intensity ratios $I_{0} / /$ versus $\mathrm{O}_{2}$ partial pressure).

oxygen. ${ }^{55}$ The Stern-Volmer plots for oxygen sensing films of these Ir(III) complexes immobilized in EC are shown in Fig. 6 . The results in Table 4 reveal that the $I_{0} / I_{100}$ values of EC film sensors immobilized with Ir 1 and Ir2 are 3.2 and 8.2, respectively. The $K_{\mathrm{SV}}^{\mathrm{app}}$ values of the Ir(III) complexes immobilized in the EC film are 0.00346 (Ir1) and 0.01346 (Ir2). It is clear that complex Ir2 with a DPA group exhibits higher oxygen sensitivity compared to that of Ir1. These results are just opposite from those in the solution. When immobilized in an EC film, Ir2 demonstrates the aggregationinduced phosphorescent emission (AIPE) due to the restriction of intramolecular motion of the DPA moiety. This is the reason why Ir2 exhibits much stronger oxygen sensitivity in the EC film than that in $\mathrm{CH}_{2} \mathrm{Cl}_{2}$. Therefore, the DPA group is crucial to enhance the oxygen sensitivity of the corresponding complex in an EC film.

\subsection{Operational stability of oxygen sensing films}

Reversibility and stability are important factors to influence the overall performance of a sensor. ${ }^{56}$ Therefore, the operational stability tests of oxygen sensing films were conducted. The emission intensity is monitored when the oxygen sensing film 
Table 4 Parameters for the $\mathrm{O}_{2}$-sensing films of $\operatorname{Ir}(\mathrm{III})$ complexes $\operatorname{Ir} 1$ and Ir2 with EC as the supporting matrix (fitting of the result to the two-site model)

\begin{tabular}{llllllll}
\hline Complexes & $I_{0} / I_{100}{ }^{a}$ & $f_{1}{ }^{b}$ & $f_{2}{ }^{b}$ & $K_{\mathrm{SV} 1}{ }^{c}$ & $K_{\mathrm{SV} 2}{ }^{c}$ & $r^{2 d}$ & $K_{\mathrm{SV}}^{\mathrm{app} e}$ \\
\hline Ir1 & 3.2 & 0.93220 & 0.06780 & 0.00371 & 0.0001 & 0.99182 & 0.00346 \\
Ir2 & 8.2 & 0.96047 & 0.03953 & 0.01401 & 0.0001 & 0.98866 & 0.01346
\end{tabular}

${ }^{a} I_{0}$ and $I_{100}$ represent the detected emission intensities in the $100 \% \mathrm{~N}_{2}$ and $100 \% \mathrm{O}_{2}$ atmosphere, respectively. ${ }^{b}$ Ratio of the two portions of the $\operatorname{Ir}\left(\right.$ III) complexes. ${ }^{c}$ Quenching constant of the two portions. ${ }^{d}$ Determination coefficients. ${ }^{e}$ Weighted quenching constant, $K_{\mathrm{SV}}^{\mathrm{app}}=$ $f_{1} K_{\mathrm{SV} 1}+f_{2} K_{\mathrm{SV} 2}$.

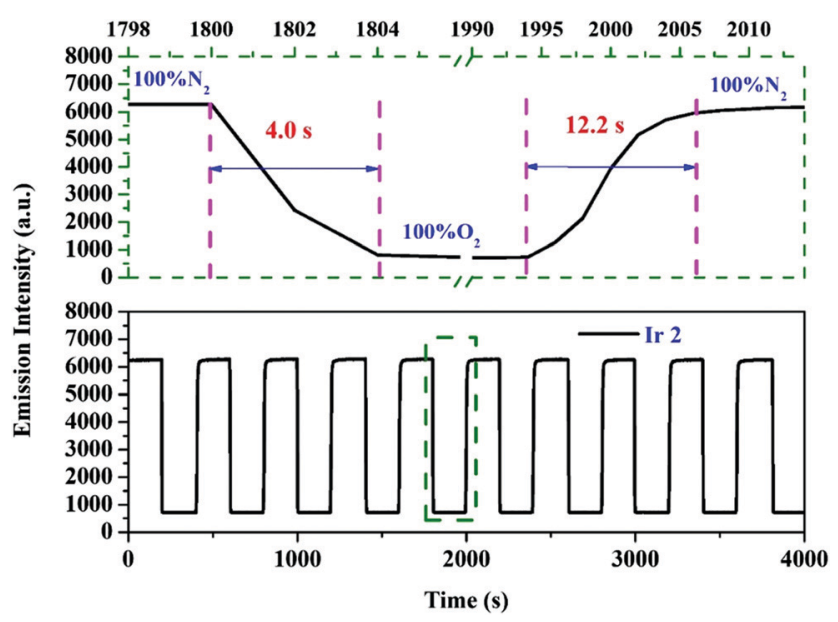

Fig. 7 Reversibility and emission intensity response of the sensing film of Ir2 immobilized in EC when cycling from $100 \% \mathrm{~N}_{2}$ to $100 \% \mathrm{O}_{2}$.

is exposed to an atmosphere which periodically varies between $100 \% \mathrm{~N}_{2}$ and $100 \% \mathrm{O}_{2}$ within 4000 s. Both the oxygen sensing films demonstrated a stable optical signal during the quenching and recovering cycles (Fig. 7 and Fig. S8 in the ESI $\dagger$ ), suggesting excellent operational stability. In addition, fast response and recovery times were obtained. Both of the sensing films demonstrate quick response times $(<4.6 \mathrm{~s}$ when changing from 0 to 100 vol\% $\left.\mathrm{O}_{2}\right)$ and recovery times $(<12.2 \mathrm{~s}$ when changing from 100 to $0 \mathrm{vol} \% \mathrm{O}_{2}$ ), respectively. Thus the oxygen sensing films of these cationic Ir(III) complexes show complete reversibility with short response times. DPA-modified cyclometalated Ir(III) complex Ir2 with excellent oxygen sensing properties is a potential candidate for online continuous monitoring of oxygen concentrations.

\section{Conclusions}

In summary, two cationic cyclometalated Ir(III) complexes Ir1 and Ir2 have been synthesized and their photophysical and electrochemical properties were studied in detail. The results demonstrate that the DPA group is an attractive substituent for tuning the properties of the corresponding Ir(III) complexes. The emission band of Ir2 with a DPA group is red-shifted $66 \mathrm{~nm}$ compared to Ir1. DPA-modified Ir(III) complex Ir2 exhibits obvious aggregation-induced phosphorescent emission, while
non-DPA-substituted Ir1 is AIPE-inactive. In addition, the introduction of a DPA moiety affects remarkably the oxygen sensitivity of the Ir(III) complex in an organic solvent and in an EC film. Immobilized in ethyl cellulose, Ir2 demonstrates high oxygen sensitivity at a $K_{\mathrm{SV}}^{\text {app }}$ value of $0.01346 \mathrm{Torr}^{-1}$. These findings might bring a useful perspective in the development of new phosphorescent materials with high performances.

\section{Experimental}

\subsection{Materials and instruments}

All starting materials were purchased from commercial suppliers and used without further purification. The solvents were treated as required prior to use. ${ }^{1} \mathrm{H}$ NMR and ${ }^{13} \mathrm{C}$ NMR spectra were recorded on a $400 \mathrm{MHz}$ Varian Unity Inova spectrophotometer. Mass spectra were recorded using a MALDI micro MX spectrometer. UV/Vis absorption spectra were recorded on an HP8453 UV/Vis spectrophotometer. Emission spectra were recorded using an F-7000 spectrofluorimeter. Photoluminescence quantum yields were measured relative to $\left[\operatorname{Ir}(\mathrm{ppy})_{2}(\mathrm{acac})\right]$ $\left(\Phi_{\mathrm{P}}=0.34\right.$ in $\mathrm{CH}_{2} \mathrm{Cl}_{2}$, under degassed conditions). Phosphorescence lifetimes were measured on an Edinburgh FLS920 Spectrometer. Cyclic voltammograms of the $\operatorname{Ir}(\mathrm{III})$ complexes were recorded on an electrochemical workstation (BAS100B/W, USA) at room temperature in a $0.1 \mathrm{M}\left[\mathrm{Bu}_{4} \mathrm{~N}\right] \mathrm{PF}_{6}$ solution under argon conditions. Phosphorescence intensity responses of sensing films of the Ir(III) complexes were recorded using an F-7000 spectrofluorimeter. DFT calculations were carried out by using B3LYP. The LanL2DZ basis set was employed for the iridium atom and the $6-31 G^{*}$ basis set was used to treat all other atoms. All these calculations were performed using the Gaussian 09 software package.

\subsection{Synthesis of cyclometalated Ir(III) complexes}

Synthesis of $\mathbf{C}^{\wedge} \mathbf{N}$ ligands. The $\mathrm{C}^{\wedge} \mathrm{N}$ ligands were synthesized by the palladium-catalyzed Suzuki-Miyaura cross-coupling reactions. $^{43}$

Synthesis of the $\operatorname{Ir}(\mathrm{III})$ complexes. Both $\operatorname{Ir}(\mathrm{III})$ complexes $\left[\operatorname{Ir}\left(\mathrm{C}^{\wedge} \mathrm{N}\right)_{2}(\right.$ phen $\left.)\right] \mathrm{PF}_{6}$ were prepared using the same procedure according to literature methods. ${ }^{38} \mathrm{IrCl}_{3} \cdot 3 \mathrm{H}_{2} \mathrm{O}$ was reacted with 2.5 equiv. cyclometalating $\mathrm{C}^{\wedge} \mathrm{N}$ ligand in a mixture of 2-ethoxyethanol and water $(9 \mathrm{~mL} / 3 \mathrm{~mL})$ at $110{ }^{\circ} \mathrm{C}$ under nitrogen for $24 \mathrm{~h}$ to afford a cyclometalated iridium bridged-chloride dimer. Without further purification the dimer was mixed with 3.0 equiv. 1,10-phenanthroline in 2-ethoxyethanol at $120{ }^{\circ} \mathrm{C}$ under nitrogen for $24 \mathrm{~h}$. After cooling down to room temperature, a 10-fold excess of $\mathrm{KPF}_{6}$ was added. The suspension was stirred for $3 \mathrm{~h}$ and washed with water and dried over $\mathrm{Na}_{2} \mathrm{SO}_{4}$. The crude product was applied to a silica gel column and eluted with $\mathrm{CH}_{2} \mathrm{Cl}_{2}$ to afford the desired Ir(III) complexes.

\section{Conflicts of interest}

The authors declare no conflict of interest. 


\section{Acknowledgements}

The authors gratefully acknowledge the financial support from the National Natural Science Foundation of China (21421005, 21276043, and U1603103) and the Talent Fund of Shandong Collaborative Innovation Center of Eco-Chemical Engineering (XTCXYX02). We thank Prof. Jianzhang Zhao at DUT for his assistance with the theoretical calculations.

\section{Notes and references}

1 F. D. Angelis, S. Fantacci, N. Evans, C. Klein, S. M. Zakeeruddin, M. Jacques-E, K. Kuppuswamy, H. J. Bolink, M. Gretzel and M. K. Nazeeruddin, Inorg. Chem., 2007, 46, 5989.

2 B. Liu, F. Dang, Z. Feng, Z. Tian, J. Zhao, W. Yong, X. Yang, G. Zhou, Z. Wu and W. Wong, J. Mater. Chem. C, 2017, 5,7871 .

3 Q. Zhao, C. Huang and F. Li, Chem. Soc. Rev., 2011, 40, 2508. 4 Y. Liu, P. Zhang, X. Fang, G. Wu, S. Chen, Z. Zhang, H. Gao, W. Tang and L. Xu, Dalton Trans., 2017, 46, 4777.

5 C. Liu, X. Lv, Y. Xing and J. Qiu, J. Mater. Chem. C, 2015, 3, 8010 .

6 R. D. Costa, E. Ortí, H. J. Bolink, F. Monti, G. Accorsi and N. Armaroli, Angew. Chem., Int. Ed., 2012, 51, 8178.

7 J. Liu, Y. Liu, Q. Liu, C. Li, L. Sun and F. Li, J. Am. Chem. Soc., 2011, 133, 15276.

8 L. Yao, J. Zhou, J. Liu, W. Feng and F. Li, Adv. Funct. Mater., 2012, 22, 2667.

9 P. Duan, N. Yanai and N. Kimizuka, Chem. Commun., 2014, 50, 13111.

10 X. Li, M. Boris, H. Ågen and H. Tian, J. Phys. Chem. C, 2011, 115, 20724.

11 J. B. Birks, Photophysics of Aromatic Molecules, Wiley-Interscience, London, 1970.

12 J. Wang, Y. Zhao, C. Dou, H. Sun, P. Xu, K. Ye, J. Zhang, S. Jiang, F. Li and Y. Wang, J. Phys. Chem. B, 2007, 111, 5082.

13 Y. Ishida, T. Shimada and S. Takagi, J. Phys. Chem. C, 2014, 118, 20466.

14 J. Luo, Z. Xie, J. W. Lam, L. Cheng, H. Chen, C. Qiu, H. S. Kwok, X. Zhan, Y. Liu, D. Zhu and B. Tang, Chem. Commun., 2001, 1740.

15 Y. Hong, J. W. Lam and B. Tang, Chem. Commun., 2009, 4332.

16 J. Mei, N. L. Leung, R. T. Kwok, J. W. Lam and B. Tang, Chem. Rev., 2015, 115, 11718.

17 M. Gao and B. Tang, Drug Discovery Today, 2017, 22, 1288.

18 J. Tavakoli, H. Zhang, B. Tang and Y. Tang, Mater. Chem. Front., 2019, 3, 664.

19 B. Manimaran, P. Thanasekaran, T. Rajendran, R. Lin, I. Chang, G. Lee, S. Peng, S. Rajagopal and K. Lu, Inorg. Chem., 2002, 41, 5323.

20 Q. Zhao, L. Li, F. Li, M. Yu, Z. Liu, T. Yi and C. Huang, Chem. Commun., 2008, 685.

21 G. Shan, D. Zhu, H. Li, P. Li, Z. Su and Y. Liao, Dalton Trans., 2011, 40, 2947.
22 D. Chao and Y. Zhang, Sens. Actuators, B, 2017, 245, 599.

23 T. Gao, J. Zhang, R. Yan, D. Cao, D. Jiang and D. Ye, Inorg. Chem., 2018, 57, 4310.

24 W. Che, G. Li, X. Liu, K. Shao, D. Zhu, Z. Su and M. R. Bryce, Chem. Commun., 2018, 54, 1730.

25 R. Liu, Z. Song, Y. Li, Y. Li, W. Yao, H. Sun and H. Zhu, Sens. Actuators, B, 2018, 259, 840.

26 Z. Song, R. Liu, H. Zhu, Y. Lu, X. Li and H. Zhu, Sens. Actuators, B, 2019, 279, 385.

27 V. Sathish, A. Ramdass, P. Thanasekaran, K.-L. Lu and S. Rajagopal, J. Photochem. Photobiol., C, 2015, 23, 25.

28 L. Ravotto and P. Ceroni, Coord. Chem. Rev., 2017, 346, 62. 29 Y. Wang, T. Yang, X. Liu, G. Li, W. Che, D. Zhu and Z. Su, J. Mater. Chem. C, 2018, 6, 12217.

30 F. Ren, P. Liu, Y. Gao, J. Shi, B. Tong, Z. Cai and Y. Dong, Mater. Chem. Front., 2019, 3, 57.

31 D. Li, G. Li, W. Che, D. Zhu and Z. Su, Dalton Trans., 2019, 48, 1955.

32 L. Zhang, Y. Li, W. Che, D. Zhu, G. Li, Z. Xie, N. Song, S. Liu, B. Tang, X. Liu, Z. Su and M. R. Bryce, Adv. Sci., 2019, 6, 1802050.

33 G. D. Marco, M. Lanza, M. Pieruccini and S. Campagna, Adv. Mater., 1996, 8, 576.

34 K. Koren, S. M. Borisov, R. Saf and I. Klimant, Eur. J. Inorg. Chem., 2011, 1531.

35 E. M. Boreham, L. Jones, A. N. Swinburne, M. BlanchardDesce, V. Hugues, C. Terryn, F. Miomandre, G. Lemercier and L. S. Natrajan, Dalton Trans., 2015, 44, 16127.

36 D. E. Achatz, R. J. Meier, L. H. Fischer and O. S. Wolfbeis, Angew. Chem., Int. Ed., 2011, 50, 260.

37 C. Liu, H. Yu, X. Rao, X. Lv, Z. Jin and J. Qiu, Dyes Pigm., 2017, 136, 641.

38 H. Yu, C. Liu, Z. Yu, L. Zhang and J. Xiu, J. Mater. Chem. C, 2017, 5, 3519.

39 Y. Xing, C. Liu, X. Song and J. Li, J. Mater. Chem. C, 2015, 3, 2166.

40 Y. Xing, C. Liu, J. Xiu and J. Li, Inorg. Chem., 2015, 54, 7783. 41 H. Yu, C. Liu, X. Lv, J. Xiu and J. Zhao, Dyes Pigm., 2017, $145,136$.

42 C. Liu, X. Song, X. Rao, Y. Xing, Z. Wang, J. Zhao and J. Qiu, Dyes Pigm., 2014, 101, 85.

43 C. Liu, X. Rao, X. Song, J. Qiu and Z. Jin, RSC Adv., 2013, 3, 526.

44 Y. Zhou, H. Gao, X. Wang and H. Qi, Inorg. Chem., 2015, 54, 1446.

45 W. Lee, T.-H. Kwon, J. Kwon, J.-Y. Kim, C. Lee and J.-I. Hong, New J. Chem., 2011, 35, 2557.

46 R. Wang, L. Deng, T. Zhang and J. Li, Dalton Trans., 2012, 41, 6833.

47 C. L. Ho, C. S. Lam, N. Sun, D. Ma, L. Liu, Z. Yu, L. Xue, Z. Lin, H. Li, Y. H. Lo and W. Y. Wong, Isr. J. Chem., 2014, 54, 999.

48 Z. Song, R. Liu, Y. Li, H. Shi, J. Hu, X. Cai and H. Zhu, J. Mater. Chem. C, 2016, 4, 2553.

49 C. L. Ho, W. Y. Wong, G. Zhou, B. Yao, Z. Xie and L. Wang, Adv. Funct. Mater., 2007, 17, 2925.

50 D. E. Achatz, R. J. Meier, L. H. Fischer and O. S. Wolfbeis, Angew. Chem., Int. Ed., 2011, 50, 260. 
51 E. R. Carraway, J. N. Demas, B. A. Degraff and J. R. Bacon, Anal. Chem., 1991, 63, 337.

52 J. N. Demas, B. A. Degraff, W. Xu and A. Chem, Anal. Chem., 1995, 67, 1377.

53 W. Wu, S. Ji, W. Wu, H. Guo, X. Wang, J. Zhao and Z. Wang, Sens. Actuators, B, 2010, 149, 395.
54 Y. Xiong, Z. Ye, J. Xu, Y. Zhu, C. Chen and Y. Guan, Analyst, 2013, 138, 1819.

55 X. Guo, Y. Liu, Q. Chen, D. Zhao and Y. Ma, Adv. Opt. Mater., 2018, 6, 1700981.

56 W. S. Lee, K. Y. Wong, X. Li, Y. B. Leung, C. S. Chan and K. S. Chan, J. Mater. Chem., 1993, 3, 1031. 